\title{
Development and application of a direct method to observe the implant/bone interface using simulated bone
}

\author{
Yoko Yamaguchi ${ }^{*}$, Makoto Shiota ${ }^{2}$, Masaki FuJii ${ }^{3}$, Michi Sekiya ${ }^{1}$ and Masahiko Ozeki ${ }^{1,4}$
}

\begin{abstract}
Background: Primary stability after implant placement is essential for osseointegration. It is important to understand the bone/implant interface for analyzing the influence of implant design on primary stability. In this study rigid polyurethane foam is used as artificial bone to evaluate the bone-implant interface and to identify where the torque is being generated during placement.

Methods: Five implant systems-Straumann-Standard (ST), Straumann-Bone Level (BL), Straumann-Tapered Effect (TE), Nobel Biocare-Brånemark MKIII (MK3), and Nobel Biocare-Brånemark MKIV (MK4)—were used for this experiment. Artificial bone blocks were prepared and the implant was installed. After placement, a metal jig and one side artificial bone block were removed and then the implant embedded in the artificial bone was exposed for observing the bone-implant interface. A digital micro-analyzer was used for observing the contact interface.
\end{abstract}

Results: The insertion torque values were $39.35,23.78,12.53,26.35$, and $17.79 \mathrm{~N} \mathrm{~cm}$ for MK4, BL, ST, TE, and MK3, respectively. In ST, MK3, TE, MK4, and BL the white layer areas were $61 \times 103 \mu \mathrm{m}^{2}, 37 \times 103 \mu \mathrm{m}^{2}, 103 \times 103 \mu \mathrm{m}^{2}$ in the tapered portion and $84 \times 03 \mu \mathrm{m}^{2}$ in the parallel portion, $134 \times 103 \mu \mathrm{m}^{2}$, and $98 \times 103 \mu^{2}$ in the tapered portion and $87 \times 103 \mu \mathrm{m}^{2}$ in the parallel portion, respectively.

Conclusions: The direct observation method of the implant/artificial bone interface is a simple and useful method that enables the identification of the area where implant retention occurs. A white layer at the site of stress concentration during implant placement was identified and the magnitude of the stress was quantitatively estimated. The site where the highest torque occurred was the area from the thread crest to the thread root and the under and lateral aspect of the platform. The artificial bone debris created by the self-tapping blade accumulated in both the cutting chamber and in the space between the threads and artificial bone.

Keywords: Primary stability, Implant design, Artificial bone, Implant/bone interface

\section{Background}

Primary stability after implant placement is essential for osseointegration. Aside from the patient's bone quantity and density, primary stability may also be affected by the implant design, including surface topography, and by the technique used to prepare the insertion socket (Friberg et al. 1995; Chiapasco et al. 1997; Javed and Romanos 2010). To analyze the influence of implant design on primary stability, it is also important to understand the

\footnotetext{
*Correspondence: blacklab87@gmail.com

1 Department of Implant Dentistry, School of Dentistry, Showa University, 2-1-1 Kitasenzoku Ota-ku, Tokyo 145-8515, Japan

Full list of author information is available at the end of the article
}

bone/implant interface. Conventionally, microscopy of animal tissue samples (Orsini et al. 2010; Ericsson et al. 1994; Duyck et al. 2001; Shalabi et al. 2006; Marin et al. 2008) or radiographic analyses have been used (Akkocaoglu et al. 2005). The former focused on the morphology of the interface only after osseointegration had occurred, whereas the latter displayed low resolution, making it difficult to standardize (Meredith 1998) and provide an accurate evaluation. In an attempt to solve these issues, a novel method was developed to observe the implant/ simulated bone interface using an artificial bone.

There are a number of reports investigating the properties of rigid polyurethane foam (PUF) for use as artificial 
bone (Thompson et al. 2003; Palissery et al. 2004; Szivek et al. 1993; Patel et al. 2008; Calvert et al. 2010). PUF is currently used as a standard orthopedic mechanical test material by the American Society for Testing and Materials (ASTM) (ASTM 2008). For mechanical testing of bone screws, the Japanese Industrial Standards recommend PUF to simulated bone, as it reproduces the dynamic characteristics of both cortical and cancellous bone (Doe 2009). The Solid Rigid Polyurethane and Cellular Rigid Polyurethane comply with the ASTM standard F1839, indicating that the materials are suitable for simulating bone to test orthopedic devices and instruments. In recent years, PUF has been used to simulated bone in dentistry for the retention of dental implants (Tabassum et al. 2009; Chong et al. 2009; Kim and Lim 2011; Kim et al. 2011; Ahn et al. 2012; Yamaguchi et al. 2015), as well as to investigate the retention of miniimplants (Lim et al. 2008; Kim et al. 2008). In this study, PUF was used evaluate the implant/simulated bone interface and to identify where the torque values is being generated during implant placement.

\section{Methods Implants}

The types of implants used for this experiment and their design characteristics are summarized in Table 1. Standard RN (ST) and Brånemark MKIII (MK3) implants are parallel design. The outer profile of the Bone Level RC (BL) implant is entirely parallel, although the inner profile is tapered only in the neck region and the thread height is reduced. For the Tapered Effect RN (TE) implant, the apical portion is parallel and the inner and outer profiles display the same taper in the neck region. The Branemark MKIV (MK4) implant has a gentle taper along the entire inner and outer profile, with a cutting chamber. $\mathrm{ST}, \mathrm{BL}$, and TE are considered non-self-tapping implants, whereas MK3 and MK4 are self-tapping implants with double-threaded.

\section{Direct observation method}

The mean bone mineral density for the posterior maxilla is $0.31 \mathrm{~g} / \mathrm{cm}^{3}$ ( 2015). The densities of used PUF $(0.32 \mathrm{~g} /$ $\mathrm{cm}^{3}$ ) were density of similar in type 4 bone density, and the following physical properties: $8.4 \mathrm{MPa}$ compressive strength, 5.6 MPa tensile strength, $4.3 \mathrm{MPa}$ shear strength, and a coefficient of elasticity of $284 \mathrm{GPa}$ (Solid Rigid polyurethane Form 20 pcf; Sawbone; pacific Research Laboratories Inc., USA) (Doe 2015).

A divided block specimen is assembled by following procedures. Four pieces of prismatic simulated bone of $1 \mathrm{~cm} \times 1 \mathrm{~cm} \times 3 \mathrm{~cm}$ were prepared, they were fixed with tape beforehand, and their circumference was fixed with metal jigs. The insertion socket was prepared in the center of the column using manufacture protocol (ASD360, Ashina, Hiroshima, Japan), avoiding movement. Each implant was installed with a load of $500 \mathrm{~g}$ and a speed of $15 \mathrm{rpm}$ (Fig. 1). The maximum insertion torquetime curve during placemen was recorded using a torque analyzer (TRQ-5DRU, PC Torque Analyzer, Vectrix, Tokyo, Japan).

After implant placement, the metal jigs and two of the simulated bone were removed carefully, the implant body was exposed. A digital micro analyzer (VHX-1000, Keyence, Osaka, Japan) and image analysis software (PopImaging, Digital Being Kids, Kanagawa, Japan) were used for observation of the implant/simulated bone interface and for image analysis, respectively. The observation of the white layer was carried out only at representative specimen that closes to average value of IT. Regression analysis examining the correlation between the area of the white layer and Torque raise rate (JMP, SAS Institute Japan, Tokyo, Japan).

\section{Results}

The insertion torque-time curves for each implant are illustrated in Fig. 2.

Implant/simulated bone interface. In ST (Fig. 3a, b), a compressed channel was observed in the implant neck. The compressed channel had smaller morphology when compared with the threads, and a subtle circular-shaped white layer could be observed around the channel. Figure 3c shows a white layer around the thread crests. The upper surface of the threads engaged the artificial bone, although a gap could be seen between the under

Table 1 Implants used in this study

\begin{tabular}{lllllll}
\hline Implant system & Length $(\mathbf{m m})$ & Diameter $(\mathbf{m m})$ & Pitch $(\mathbf{m m})$ & Lead $(\mathbf{m m})$ & Code & Manufacturer \\
\hline Standard RN & 10 & 4.1 & 1.2 & 1.2 & ST & Straumann \\
Bone level RC & 10 & 4.1 & 0.8 & 0.8 & TE & Straumann \\
Tapered effect RN & 10 & 4.1 & 0.6 & 0.8 & TE & Straumann \\
Brånemark MKIII & 10 & 3.75 & 0.6 & 1.2 & MK3 & Nobel Biocare \\
Brånemark MKIV & 10 & 4.0 & 1.2 & MK4 & Nobel Biocare \\
\hline
\end{tabular}




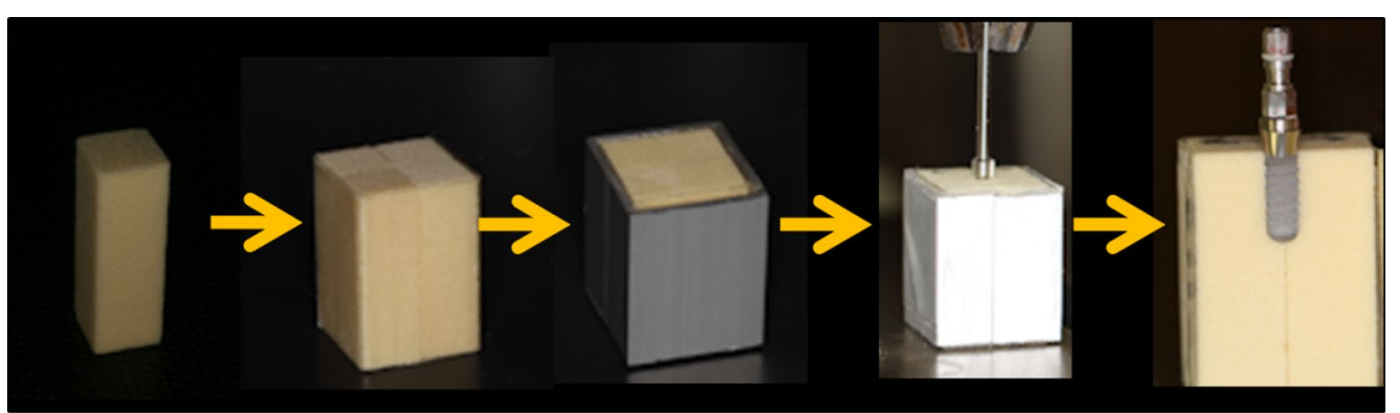

Fig. 1 Flow of a divided block specimen. Four divided block specimen was assembled by tape. Their circumference was fixed with metal jigs and the implant was inserted according to the manufacturer instructions. After the placement, the metal jigs and two of the divided block were removed carefully

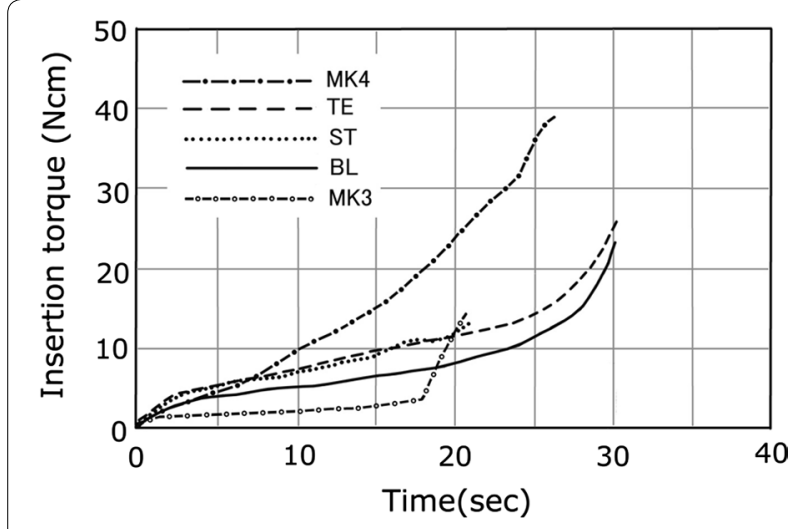

Fig. 2 Torque-time curves for average insertion value of MK4,TE, ST, $\mathrm{BL}, \mathrm{MK} 3$ implant

thread and the thread root. The area of the white layer was approximately $61 \times 103 \mu \mathrm{m}^{2}$.

In $\mathrm{MK} 3$, a gap between the tapped channel and the threads was also observed (Fig. 4a, b). The debris regarded as artificial bone chips were scattered along the implant surface and observed abundantly in the cutting chamber. A white layer could be observed around the threads, and debris could easily be removed by airblowing. The thread crests closely engaged the artificial bone, although a gap could be seen under to the threads extending to the thread root. The white layer on the thread crest was $37 \times 103 \mu \mathrm{m}^{2}$ (Fig. 4c).

In TE, a gap was observed between the inner profile of the implant and the artificial bone (Fig. 5a). In the tapered portion, approximately half of the thread height engaged the artificial bone and a circular-shaped white layer were observed around the thread ridge (Fig. 5b, c). The upper threads closely engaged the artificial bone, although a gap could be seen between the under surface of the threads and the threads root. The white layer was $103 \times 103 \mu \mathrm{m}^{2}$ in the tapered portion (B) and $84 \times 103 \mu \mathrm{m}^{2}$ in the parallel portion $(C)$.

In MK4, slight gaps were observed along the entire implant and artificial bone interface (Fig. 6a). The cutting debris on the implant surface and thread root (Fig. 6b). The debris was removed and a gap was then observed around the thread root, and white layers were observed around both the thread crest and root. The white layer was $134 \times 103 \mu \mathrm{m}^{2}$ (Fig. 6c).

In $\mathrm{BL}$, the upper thread surface closely engaged the artificial bone, and a gap was observed the thread root (Fig. 7a, b). The white layer surrounding the threads was $98 \times 103 \mu^{2}$ in the tapered portion (B) and $87 \times 103 \mu \mathrm{m}^{2}$ in the parallel portion $(C)$.

Table 2 shows the white layer corresponds with the torque value. Regression analysis examining the correlation between the white layer area and torque raise rate, the correlation coefficient is 0.617566 , slope 0.019372 , intercept 0.60584 is obtained, a positive correlation was observed.

\section{Discussion}

The bone density of used PUF was similar to other reports (Tabassum et al. 2009; Bayarchimeg et al. 2013), and the PUF is homogeneous consistency and eliminate anatomical or structural differences of biological samples to IT evaluate better the effects of the implant design (Tabassum et al. 2009). Furthermore, PUF exhibit stressstrain behaviors similar to trabecular bone (Calvert et al. 2010). The novel direct observation method devised for this study enables the center of the implant to be exposed without becoming destruction of the specimen; therefore, the implant/artificial bone interface could be observed successfully.

The insertion torque values provides more accurate data for the retention of an implant (Friberg et al. 1995; Homolka et al. 2002; Sakoh et al. 2006; Atsumi et al. 

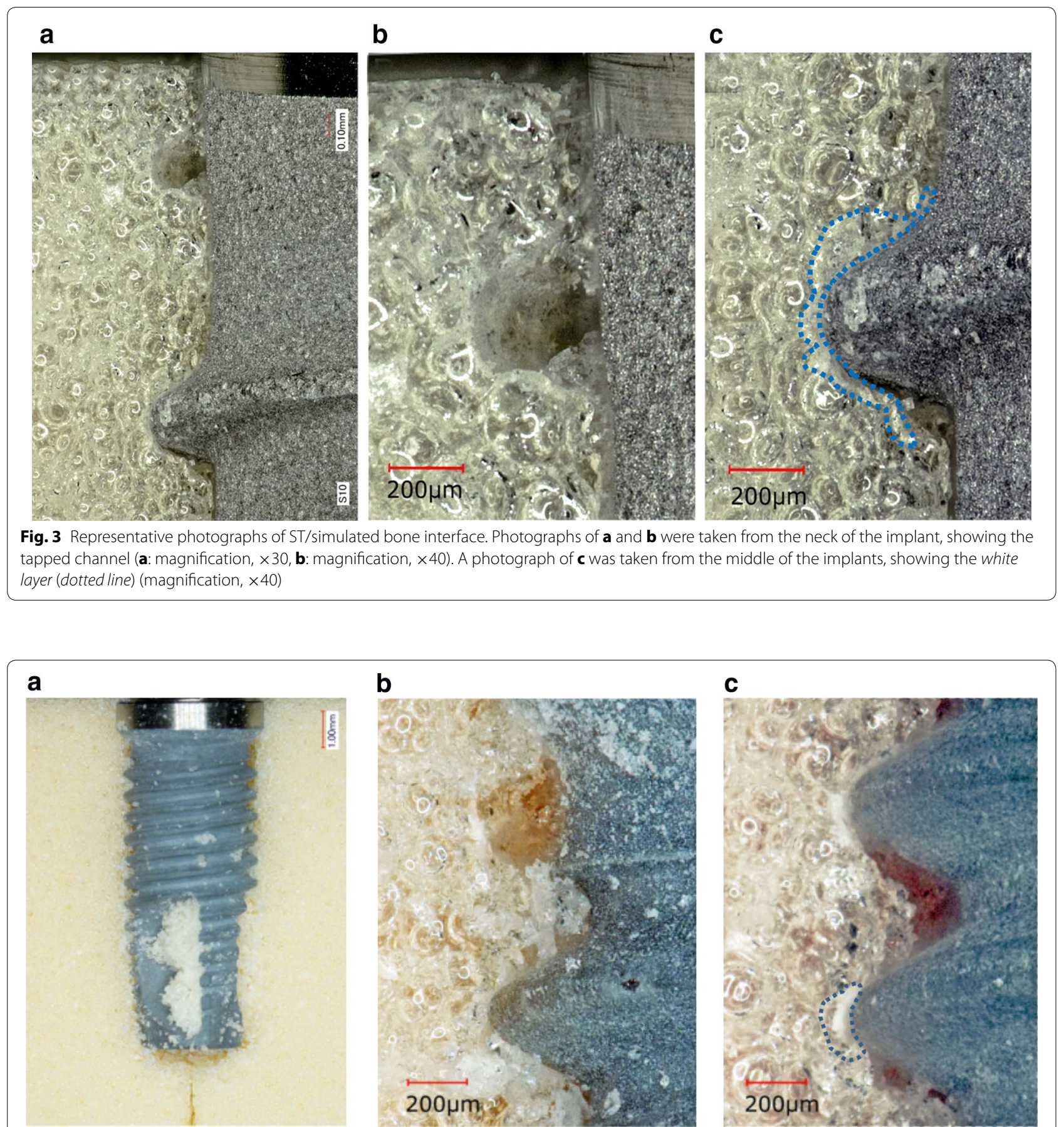

Fig. 4 Representative photographs of MK3/simulated bone interface. Debris was scattered overall implant body and the cutting chamber (a: magnification, $\times 3$ ). A photograph of $\mathbf{b}$ was taken from the neck of the implant, showing the tapped channel (magnification, $\times 30$ ). A photograph of c was taken from the middle of the implant, showing the space between the under implant threads to the root (magnification, $\times 30$ )

2007). The implant design affects the insertion torque values (O'Sullivan and Sennerby 2000). This study revealed that the white layer corresponds with the insertion torque to some degree. Differences in insertion torque value were related to differences in the morphology of the white layer. The relationship between the white layer area of the parallel and tapered sections with torque raise rate. The white layer area remains small when the implant design is parallel and torque increases gradually. The white layer area remains wide when a tapered design is 

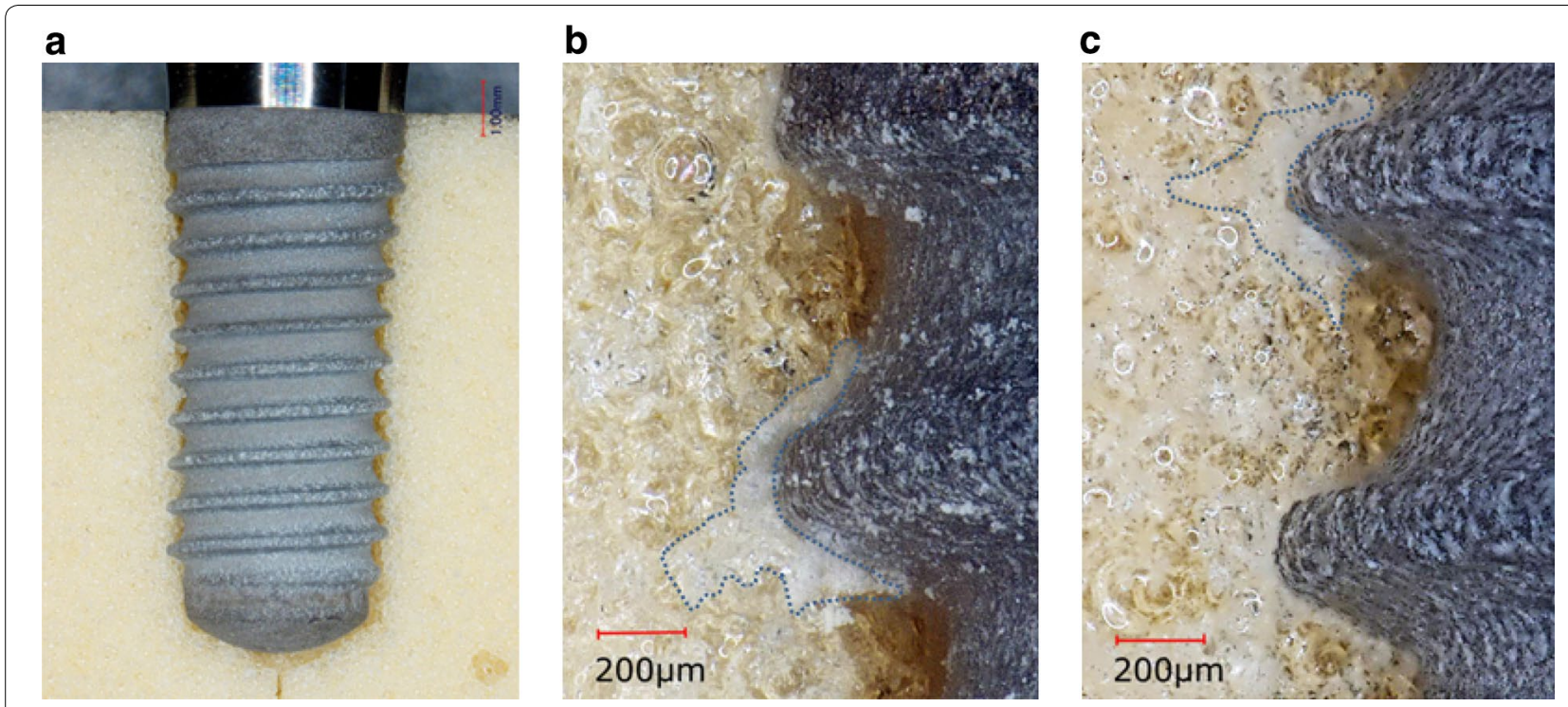

Fig. 5 Representative photographs of TE/simulated bone interface. A photograph of a was showing the space between threads (magnification, $\times 5$ ). A photograph of $\mathbf{b}$ was taken from the neck of the implants (tapered portion) (magnification, $\times 40$ ) and $\mathbf{c}$ was taken from the middle of the implant, both showing the white layer (dotted line) and the space between the under implant threads to the root (magnification, $\times 40$ )
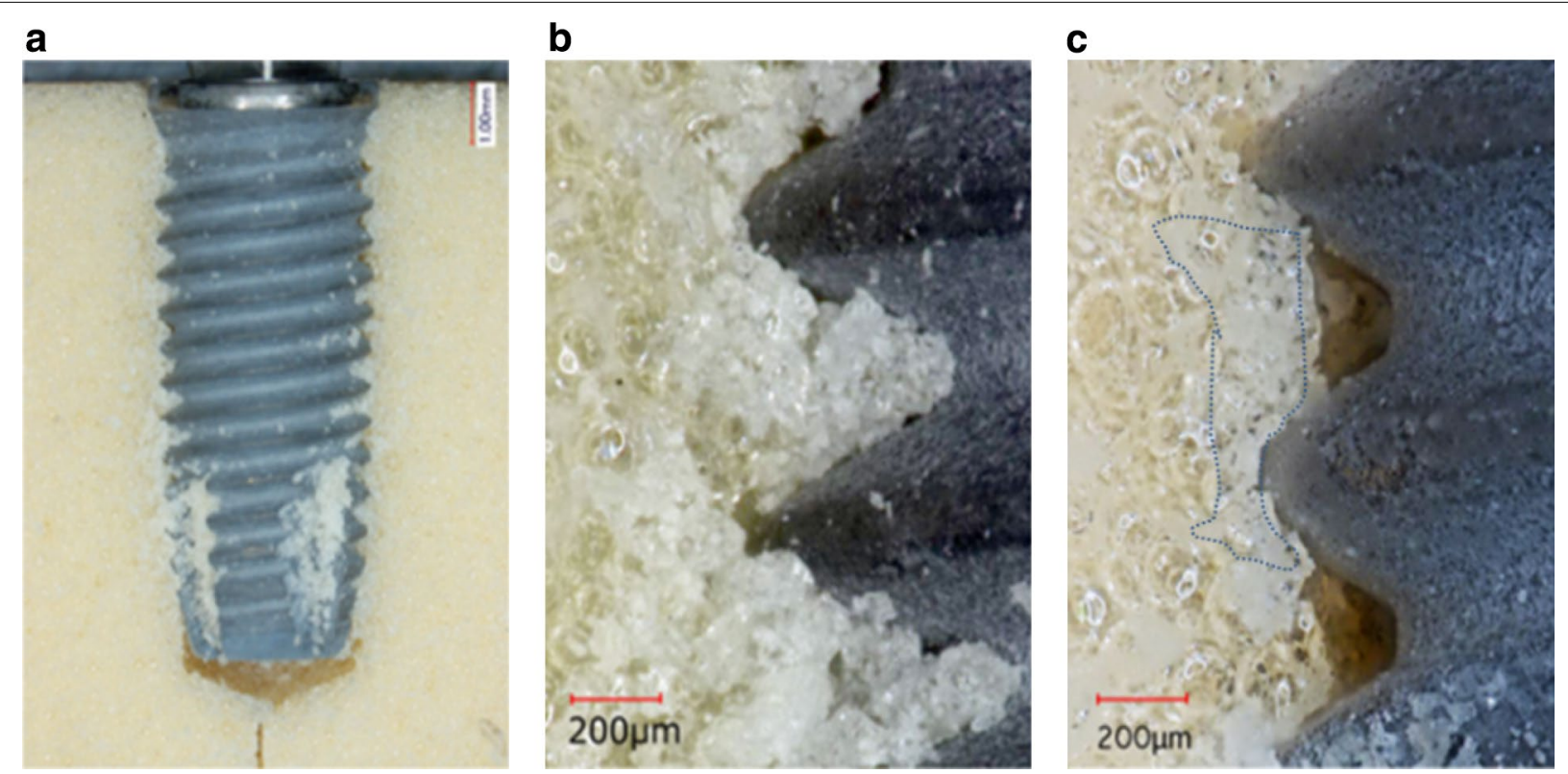

Fig. 6 Representative photographs of MK4/simulated bone interface. Debris was scattered overall implant body and the cutting chamber (a: magnification, $\times 4$ ). A photograph of $\mathbf{b}$ and $\mathbf{c}$ was taken from the middle of the implant (magnification, $\times 40$ ), and $\mathbf{b}$ was showing debris in the threads root, and after air-blowing of $\mathbf{c}$ was showing the white layer (dotted line), the space realized thread root (magnification, $\times 40$ )

used and the torque increases suddenly. A limitation of the direct method used to observe the implant/artificial bone interface is disturbance and spreading of the blocks when the insertion torques becomes large. Therefore, it is necessary to securely fix the blocks assembly using metal jigs and to ensure that the specimen is correctly placed by measuring the insertion torque values.

The white layers were observed around the implant threads in all specimens. The area of the white layers varied, and included the thread crests, circular-shaped sites 


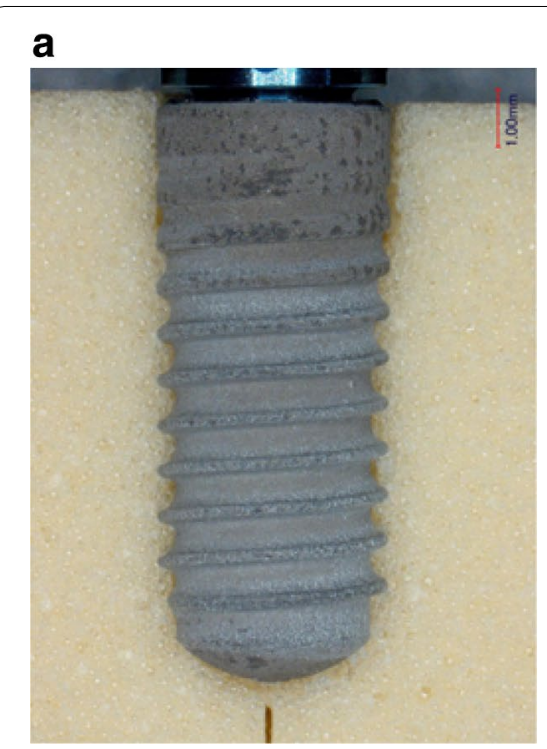

b

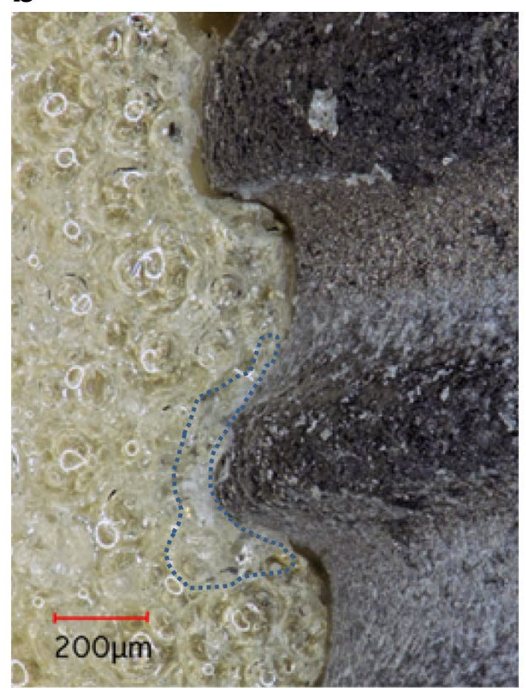

c

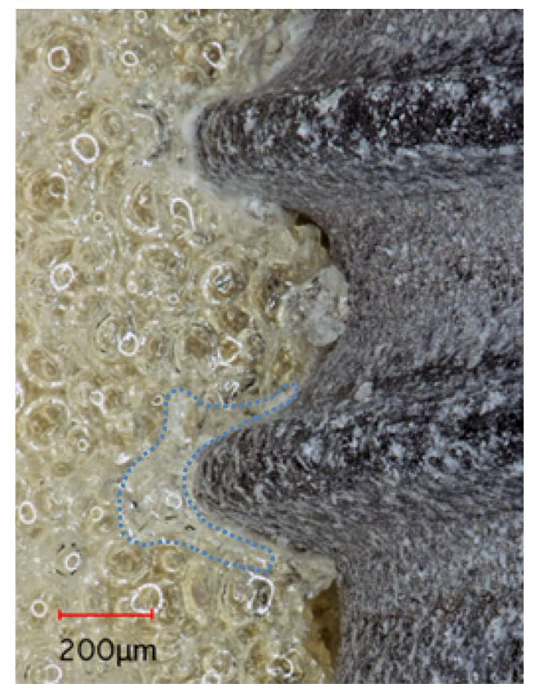

Fig. 7 Representative photographs of BL/simulated bone interface. A photograph of $\mathbf{a}$ was showing the tapered portion engaged the simulated bone (magnification, $\times 5$ ). A photograph of $\mathbf{b}$ was taken from the neck of the implant, showing the white layer (dotted line) (magnification, $\times 40)$. A photograph of $\mathbf{c}$ was taken from the middle of the implants, showing the white layer (dotted line) (magnification, $\times 40$ )

Table 2 Area of white layer and torque rise rate of each implant

\begin{tabular}{llcl}
\hline Implant & Portion & $\begin{array}{l}\text { Area of white layer } \\
\left(\mathbf{x} \mathbf{1 0 3} \boldsymbol{\mu m}_{\mathbf{2}}\right)\end{array}$ & $\begin{array}{l}\text { Torque rise rate } \\
(\mathbf{N} \mathbf{~ c m} / \mathbf{s})\end{array}$ \\
\hline ST & Parallel & 61 & 0.45 \\
MK3 & Parallel & 37 & 0.13 \\
TE & Parallel & 84 & 0.45 \\
BL & Parallel & 87 & 0.35 \\
TE & Taper & 103 & 2.31 \\
MK4 & Taper & 134 & 1.32 \\
BL & Taper & 98 & 2.45 \\
\hline
\end{tabular}

around the thread ridges, and thread roots. Some areas were belt-shaped with a constant width and in other areas, the white layer spread deeply from the crest of the threads.

The comparing the IT of self-tapping and non-selftapping implants were resulted the self-tapping implant higher insertion values than with non-self-tapping implants in a clinical study (Marković et al. 2013). The conical Implant compared with cylindric screw-type implant resulted in higher primary stability in soft bone (Sakoh et al. 2006). The primary stability of five implant designs was compared in fresh human cadavers. In type 4 bones, the MkIV Brånemark implant maintained a high primary stability in compare with all other types tested (O'Sullivan and Sennerby 2000). However, when measuring the area of these white layers, it was found that self-tapping straight implant of MK3 had the smallest, followed by ST, BL, TE, and self-tapping tapered implant of MK4. Therefore, this result could be the implant macro-design (e.g. tapered and straight) effect to IT than cutting chamber. This order correlates with the implant torque values, suggesting that the size of the white layer is closely related to insertion torque values. It is presumed that the white layer occurs when the cell structure of the artificial bone is damaged by an external force, with variations in reflection factor and refractive index causing the area to become cloudy. Therefore, the location of the white layer is thought to correspond with the site of stress concentration. In addition, if the size of the white layer does indeed correspond with stress, it could be used to indicate the location, direction, and magnitude of force acting on the artificial bone. The present study showed that the IT and white layer increased according to the tapered portion, resulting in a positive correlation. In other words, the primary stability was shown to be highly dependent on the implant design.

Observing the interface between the threads and artificial bone in detail, the upper threads closely engaged the artificial bone, whereas the under did not contact the artificial bone closely, resulting in the presence of a gap. Based on this observation, it is believed that primary stability of the implants was mainly dependent on the friction between the upper surface of the threads and the bone. Potential causes for the gap under to the threads are as follows. During insertion, a rotational force is used to extend the implant into the artificial bone, resulting in slight expansion of the implant as the under thread 
surfaces rotate and compress the artificial bone upon contact. However, once the rotational force disappears, the implant shrinks by elastic recovery. This shrinkage results in a separation between the under thread surfaces and the bone. In ST and MK3, the parallel implant groups, the threads contacted the artificial bone at the neck. This was a characteristic finding of the parallel implants as it was not observed with tapered implants. This gap was slightly smaller than that noted between the artificial bone and the threads positioned further apically. It is suggested that the elastic recovery force holed the threads and enhanced retention of the implant. The implant platform in MK3 and MK4 engaged the artificial bone closely and no gap was seen. However, white layers such as those around the threads were not observed. The insertion torque-time curves showed that a greater torque values was generated when the platform contacted the bone. This is presumably because the surface where the platform contacted the bone was large and flat, and therefore the force was dispersed and did not create sufficient plastic deformation to destroy the foam. For self-tapping implant of MK3 and MK4, it was confirmed that the bone debris, which occurred during tapping, were distributed over the contacting interface. This study revealed that most of the bone debris was accumulated in the chamber, although some were simultaneously accumulated in the gap between the threads and artificial bone. Therefore, it is thought that a greater decrease in reverse torque occurred because of the bone debris on the contact interface being gradually fragmented and flattened. One of the causes early lost might flattening of the irregularities of the contact area.

\section{Conclusions}

The limitation of this study is that only the correlations of mechanical retention and implant design were evaluated, whereas in clinical situations many biological factors affect primary stability. However, the novel direct observation method of the implant/artificial bone interface is a simple and useful that enables the identification of the area where implant retention occurs. Artificial bone composed a white layer at the site of stress concentration during implant placement; therefore, sites loaded by stress were identified and the magnitude of the stress was quantitatively estimated.

\section{Abbreviations \\ PUF: polyurethane foam; ST: standard RN; BL: bone level RC; TE: tapered effect RN; MK4: Brånemark MKIV; MK3: Brånemark MKIII.}

\section{Authors' contributions}

YY participated in the sequence alignment concept/design, data collection, data analysis, drafted manuscript. MS helped to concept/design and drafted manuscript. MF and MS helped to data collection. MO participated critical revision of article. All authors read and approved the final manuscript.

\section{Author details}

${ }^{1}$ Department of Implant Dentistry, School of Dentistry, Showa University, 2-1-1 Kitasenzoku Ota-ku, Tokyo 145-8515, Japan. ${ }^{2}$ Division of Oral Health Sciences, Department of Masticatory Function Rehabilitation, Oral Implantology and Regenerative Dental Medicine, Graduate School, Tokyo Medical and Dental University, 1-5-45 Yushima, Bunkyo-ku, Tokyo 113-8510, Japan. ${ }^{3}$ Dental Implant Clinic, Dental Hospital, Tokyo Medical and Dental University, 1-5-45 Yushima, Bunkyo-ku, Tokyo 113-8510, Japan. ${ }^{4}$ Dental Implant Center, Showa Dental Hospital, 2-1-1 Kitasenzoku Ota-ku, Tokyo 145-8515, Japan.

\section{Acknowledgements}

The authors thank the Vectrix Corporation and Director Kazuhiro Konagai for the consultation of the torque analyzer.

\section{Competing interests}

The authors declare that they have no competing interests.

Received: 6 January 2016 Accepted: 6 April 2016

Published online: 21 April 2016

\section{References}

Ahn SJ, Leesungbok R, Lee SW, Heo YK, Kang KL (2012) Differences in implant stability associated with various methods of preparation of implant bed: an in vitro study. J Prosthet Dent 107(6):366-372. doi:10.1016/ S0022-3913(12)60092-4

Akkocaoglu M, Uysal S, Tekdemir I, Akca K, Cehreli MC (2005) Implant design and intraosseous stability of immediately placed implants: a human cadaver study. Clin Oral Impl Res 16:202-209

ASTM (2008) F1839, standard specification for rigid polyurethane foam for use as a standard material for testing orthopaedic devices and instruments. American Society for Testing and Materials. West Conshohocken: ASTM. doi:10.1520/F1839-08

Atsumi M, Park SH, Wang HL (2007) Methods used to assess implant stability: current status. Int J Oral Maxillofac Implants 22:743-754

Bayarchimeg D, Namgoong H, Kim BK, Kim MD, Kim S, Kim TI, Seol YJ, Lee YM, Ku Y, Rhyu IC, Lee EH, Koo KT (2013) Evaluation of the correlation between insertion torque and primary stability of dental implants using a block bone test. J Periodontal Implant Sci 43(1):30-36. doi:10.5051/ jpis.2013.43.1.30

Calvert KL, Trumble KP, Webster TJ, Kirkpatrick LA (2010) Characterization of commercial rigid polyurethane foams used as bone analogs for implant testing. J Mater Sci Mater Med 21(5):1453-1461. doi:10.1007/ s1 0856-010-4024-6

Chiapasco M, Gatti C, Rossi E, Haeflige W, Markwaldel TH (1997) Implantretained mandibular overdentures with immediate loading: a retrospective multicenter study on 226 consecutive cases. Clin Oral Implants Res 8:48-57

Chong L, Khocht A, Suzuki JB, Gaughan J (2009) Effect of implant design on initial stability of tapered implants. J Oral Implantol 35(3):130-135. doi:10.1563/1548-1336-35.3.130

Doe J (2015) JIS T0311:2009. Mechanical testing methods for metallic bone screws. Japanese Industrial Standards Committee. https://www.jisc.go.jp. Accessed 16 Dec 2015

Doe J (2015) Sawbone block 20 PCF. http://www.sawbones.com. Accessed 16 Dec 2015

Duyck J, Renold HJ, Van Oosterwyck H, Naert I, Vander Sloten J, Ellingsen JE (2001) The influence of static and dynamic loading on marginal bone reactions around osseointegrated implants: an animal experimental study. Clin Oral Implants Res 12:207-218

Ericsson I, Johansson CB, Bystedt H, Norton MR (1994) A histomorphometric evaluation of bone-to-implant contact on machine-prepared and roughened titanium dental Implants. Clin Oral Implants Res 5:202-206

Friberg B, Sennerby L, Roos J, Johansson P, Strid CG, Lekholm U (1995) Evaluation of bone density using cutting resistance measurements and microradiography. An in vitro study in pig ribs. Clin Oral Implants Res 6:164-171

Homolka P, Beer A, Birkfellner W, Nowotny R, Gahleitner A, Tschabitscher M, Bergmann H (2002) Bone mineral density measurement with dental 
quantitative $\mathrm{CT}$ prior to dental implant placement in cadaver mandibles: pilot study. Radiology 224:247-252

Javed F, Romanos GE (2010) The role of primary stability for successful immediate loading of dental implants. A literature review. J Dent 38:612-620

Kim YS, Lim YJ (2011) Primary stability and self-tapping blades: biomechanical assessment of dental implants in medium-density bone. Clin Oral Implants Res 22(10):1179-1184. doi:10.1111/j.1600-0501.2010.02089.x. (Epub)

Kim JW, Baek SH, Kim TW, Chang YI (2008) Comparison of stability between cylindrical and conical type mini-implants. Angle Orthod 78(4):692-698. doi:10.2319/060407-266.1

Kim DR, Lim YJ, Kim MJ, Kwon HB, Kim SH (2011) Self-cutting blades and their influence on primary stability of tapered dental implants in a simulated low-density bone model: a laboratory study. Oral Surg Oral Med Oral Pathol Oral Radiol Endodontol 112(5):573-580. doi:10.1016/j. tripleo.2010.12.001 (Epub 2011 Mar 24)

Lim SA, Cha JY, Hwang CJ (2008) Insertion torque of orthodontic miniscrews according to changes in shape, diameter, and length. Angle Orthod 78(2):234-240. doi:10.2319/121206-507.1

Marin C, Granato R, Suzuki M, Gil JN, Piattelli A, Coelho G (2008) Removal torque and histomorphometric evaluation of bioceramic grit-blasted/ acid-etched and dual acid-etched implant surfaces: an experimental study in dogs. J Periodontol 79:1942-1949

Marković A, Calvo-Guirado JL, Lazić Z, Gómez-Moreno G, Ćalasan D, Guardia J, Čolic S, Aguilar-Salvatierra A, Gačić B, Delgado-Ruiz R, Janjić B, Mišić T (2013) Evaluation of primary stability of self-tapping and non-self-tapping dental implants. Clin Implant Dent Relat Res 15(3):341-349

Meredith N (1998) Assessment of implant stability as a prognostic determinant. Int J Prosthodont 11:491-501

Orsini E, Giavaresi G, Trire A, Ottani V, Salgarello S (2010) Dental implant thread pitch and its influence on the osseointegration process: an in vivo comparison study. Int J Maxillofac Implants 2:383-392
O'Sullivan D, Sennerby L, Meredith N (2000) Measurements comparing the initial stability of five designs of dental implants: a human cadaver study. Clin Implant Dent Relat Res 2:85-92

Palissery V, Tayler M, Browne M (2004) Fatigue characterization of a polymer foam to use as a cancellous bone analog material in the assessment of orthopaedic devices. J Mater Sci Mater Med 15:61-67. doi:10.1023/B:JMS M.0000010098.65572.3b

Patel P, Shepherd D, Hukins D (2008) Compressive properties of commercially available polyurethane foams as mechanical models for osteoporotic human cancellous bone. BMC Musculoskelet Disord 9:137. doi:10.1186/1471-2474-9-137

Sakoh J, Wahlmann U, Stender E, Nat R, Al-Nawas B, Wagner W (2006) Primary stability of a conical implant and a hybrid, cylindric screw-type implant in vitro. Int J Oral Maxillofac Implants 21:560-566

Shalabi MM, Wolke JGC, Jansen JA (2006) The effects of implant surface roughness and surgical technique on implant fixation in an in vitro model. Clin Oral Implants Res 17:172-178

Szivek JA, Thomas M, Benjamin JB (1993) Characterization of a synthetic foam as a model for human cancellous bone. J Apple Biomater 4:269-272. doi:10.1002/jab.7700-40309

Tabassum A, Meijer GJ, Wolke JG, Jansen JA (2009) Influence of the surgical technique and surface roughness on the primary stability of an implant in artificial bone with a density equivalent to maxillary bone: a laboratory study. Clin Oral Implants Res 20(4):327-332. doi:10.1111/j.1600-0501.2008.01692.x

Thompson MS, McCarthy ID, Lidgren L, Ryd L (2003) Compressive and shear properties of commercially available polyurethane foams. J Biomech 125:732-734. doi:10.1115/1.1614820

Yamaguchi Y, Shiota M, Munakata M, Kasugai S, Ozeki M (2015) Effect of implant design on primary stability using torque-time curves in artificial bone. Int J Implant Dent 1:21. doi:10.1186/s40729-015-0024-0

\section{Submit your manuscript to a SpringerOpen ${ }^{\circ}$ journal and benefit from:}

- Convenient online submission

- Rigorous peer review

- Immediate publication on acceptance

- Open access: articles freely available online

- High visibility within the field

- Retaining the copyright to your article

Submit your next manuscript at $\boldsymbol{\nabla}$ springeropen.com 